\title{
A METHOD FOR PREDICTING THE DIRECT TRANSMITTANCE OF ATMOSPHERIC AEROSOL FOR SOLAR RADIATION MODELS.
}

(Received 25 July, 2003; Revision Accepted 15 October. 2003)

\begin{abstract}
This paper presents a proposed method for predicting the transmittance of aerosol in the atmosphere for solar radiation models. The results from the application of the developed expression have been used to check its consistency with that of a universal direct solar transmittance model due to King and Buckius (1979) for 'clear atmosphere' and 'haze atmosphere' coriditions. The trends in the variations of the two models are identical but the disparity in the magnitudes of the transmittances tends to widen with increasing value of air mass under the specified conditions, particularly for air masses $\geq 20$. Appropriate reasons have been given for the observed differences. It is proposed that the developed model may be relevant for the prediction of the transmittances of gases at different strata of the atmosphere for solar radiation modeis', provided the 'scaled heights' of the gases are known.
\end{abstract}

KEYWORDS: Transmittance, atmospheric aerosols, clear atmosphere, haze atmosphere, scaled heights.

\section{INTRODUCTIÓN}

The knowledge of the availability and intensity of solar irradiance on the earth's surface is important in building heating load calculations and other passive and active applications across several environments.

Scattering and absorption of solar radiation by the atmospheric constituents (aerosols, mixed gases, water vapour, ozone and clouds, etc.) result in a remarkable attenuation of the incoming solar beam.

The net global (direct and diffuse) solar radiation that eventually arrives at the earth's surface is thus drastically modified. While water vapour and ozone are unquestionably the principal absorbers of incident solar radiation, the absorption due to the uniformly mixed gases, molecular oxygen $\left(\mathrm{O}_{2}\right)$, carbon dioxide $\left(\mathrm{CO}_{2}\right)$, methane $\left(\mathrm{CH}_{4}\right)$, nitrous oxide $\left(\mathrm{N}_{2} \mathrm{O}\right)$, carbon monoxide (CO) and aerosols is often neglected.

The relative concentration of the uniformly mixed gases does not vary with height, unlike the unmixed gases such as $\mathrm{H}_{2} \mathrm{O}, \mathrm{O}_{3}$, and $\mathrm{HNO}_{3}$ whose concentrations are height dependent. The unmixed gases have strong absorption bands within the solar spectrum and exert a varying influence on the incoming solar radiation (Prasad et al., 1987).

Measurements have been carried out on the concentration of methane $\left(\mathrm{CH}_{4}\right)$ in the earth's atmosphere with conclusions that it is uniformly mixed at all heights. I. ater investigations showed that methane's volume mixing ratio was constant with height in the troposphere $60-12 \mathrm{~km}$ approximately) but decreases linearly in the stratosphere $(12-30 \mathrm{~km})$ with slight seasonal variations (Psiloglou et al., 1995).

Prediction methods for most of the major atmospheric absorbers are available in the literature (Bird and Hulstrom, 1981; Santamouris and Rigopoulus; 1987; Louche et al., 1987; Maduekwe and Oshodi-Glover, 1995; Rapti, 2000). Several workers (Hogt, 1978; Bird and Hulstrom, 1982; Santamouris et al., 1985; Psiloglou et al., 1994) have also evaluated the integral transmission function of the uniformly mixed gases as functions of some solar variables. In other words, the transmittarice of radiation through the earth's atmosphere is a function of several individual transmitance of each component of atmospheric gases namely the transmittance by water vapour, the transmittance by Rayleigh scatterirg, the transmittance by ozone and the transmittance due to aerosols (defined as the suspension of fine liquid and / or solid particles in $a$ gas). In the earth's atmosphere, the term aerosol refers to the class of liquid or solid particles with radii between 0.001 and $50 \mu \mathrm{m}$.

Majority of the different types of aerosols such as smoke particles, gas-to-particle species from industries, transportation and wastes formed by chemical reactions of a variety of trace gases are prevalent in the troposphere. Volcanic type of atmospheric aerosol from volcanic materials such as dusi ash and gas injected into the atmosphere are prevalent in the stratosphere.

In this paper, a simple expression for the integral transmission function is developed to represent the transmittance through aerosols in the atmosphere in relation to the sun's zenith angle, appropriately converted to air mass via a simple expression relating the two parameters. A brief application is given and the results compared with that of a universal direct solar transmittance model proposed by King and Buckius (1979), for both 'clear' and 'haze' atmospheres.

\section{Equation for the attenuation of radiation}

The equation for the attenuation of solar radiation as it traverses downwards through the atmosphere is developed along the lines used by Chapman (1931) for photoionization in the atmosphere.

Considering the complex nature of the variations of the atmospheric parameters, Chapman made the following simplifying assumptions:

i. The radiation is monochromatic with a photon flux $S(h)$.

ii. The atmosphere is plane and horizontally stratified. 
Table 1: Computed values of the integral transmittance for aerosol particles.

\begin{tabular}{|ccc|} 
Air mass $(\mathrm{m})$ & $\begin{array}{c}\text { Aerosol Transmittance } \tau \\
(\mathbf{z}=3.47)\end{array}$ & $(\mathbf{z}=3.80)$ \\
\hline 10 & 0.73 & 0.80 \\
15 & 0.63 & 0.72 \\
20 & 0.54 & 0.64 \\
25 & 0.46 & 0.57 \\
30 & 0.39 & 0.51 \\
25 & 0.34 & 0.46 \\
40 & 0.30 & 0.41 \\
45 & 0.25 & 0.37 \\
50 & 0.21 & 0.33 \\
\hline
\end{tabular}

iii. The : atmosphere consists of a single absorbing gas with number density $n(h)$

Radiation enters the atmosphere at a zenith angle $\chi$. Its intensity is $S_{\infty}$ on the top of the atmosphere and $S$ at a reference altitude $h$ from the ground as shown in Figure 1.

The intensity of the radiation changes with distance as:

$$
d S=q \text { Sec } \chi d h
$$

where $q$ denotes the number of electrons produced per second in a unit volume.

The number of electrons produced is proportional to the product of particle density and photon flux. Hence,

$$
q=n \delta S
$$

where $\delta$ is the absorption cross-section of the radiation in the gas.

The law of gaseous equilibrium gives:

$$
n=n_{0} \exp (-z)
$$

$n_{0}$ is the number density at the reference level and $z$ is the "reduced height".

Combining equations (1), (2) and (3), we have:

$$
d S=n_{0} \delta S \exp (-z) \operatorname{Sec} \chi d h
$$

where

$$
z=h / H
$$

$$
H=\frac{K T}{m g}=\frac{R T}{M g}
$$

$H$ is known as the scale height of the gas and $z$ as the reduced height (measured in units of $H$ ). $T$ is temperature, $\quad \mathrm{K}$ is Boltzmann constant, $m$ is particle mass, $g$ is acceleration due to gravity, $R$ is gas constant and $M I$, the molar mass.

Equation (4) may thus be re-written as:

$$
\frac{d S}{S}=n_{0} \delta I H \operatorname{Sec} \chi \exp (-z) d z
$$

The reference level in the atmosphere may be chosen for $n$ or $h$, such that $n_{0} \delta H=1$.

Hence, equation (7) becomes:

$$
\frac{d S}{S}=\operatorname{Sec} \chi \exp (-z) d z
$$

Integrating equation (8), we have:

$$
\begin{aligned}
& \ln \frac{S}{S_{\infty}}=\operatorname{Sec} \chi \int_{\infty}^{z} \exp (-z) d z \\
& \ln \frac{S}{S_{\infty}}=-\operatorname{Sec} \chi[\exp (-z)] .
\end{aligned}
$$

The instantaneous attenuated solar radiation $S$ for all wavelengths is then given by the expression:

$$
S=S_{\infty} \exp [-\exp (-z) \sec \chi]
$$

where $S_{\infty}=1.38 \mathrm{KWm}^{-2}$ (Ohvril, et al., 1999) is the solar constant (the unattenuated solar radiation at the top of the atmosphere) and the transmittance, $\tau$ of the aerosol particles is given as:

$$
\tau=\frac{S}{S_{\infty}}=\exp [-\exp (-z) \operatorname{Sec} \chi]
$$

and

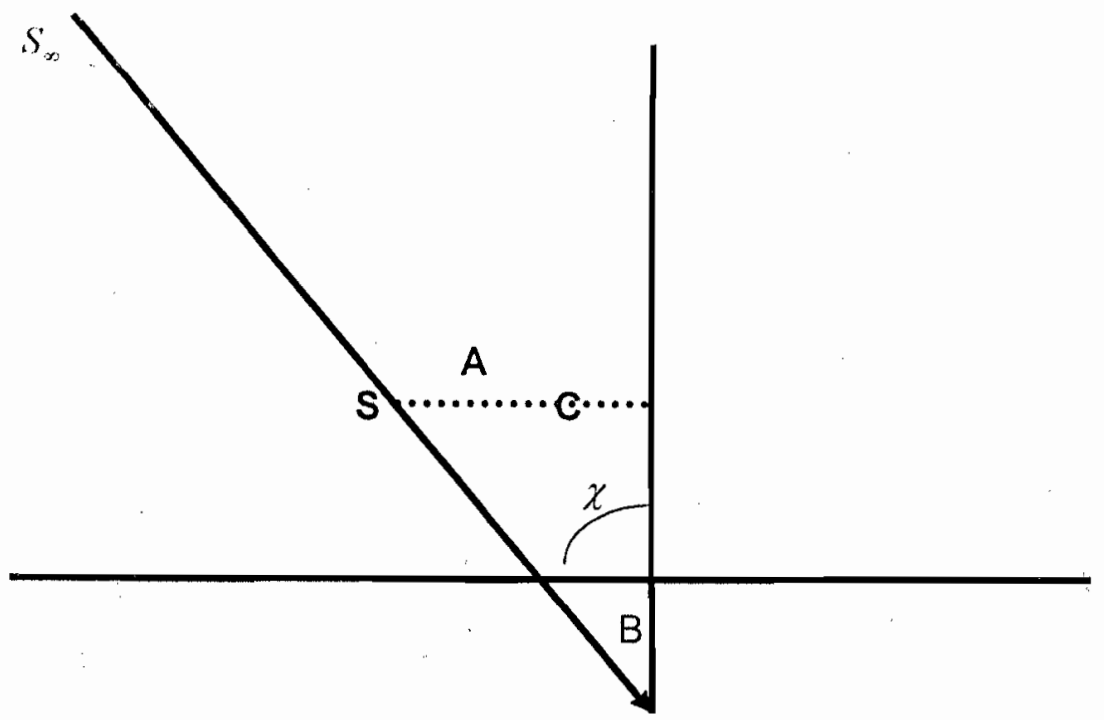

Figure 1: Flow of radiation in the atmosphere 


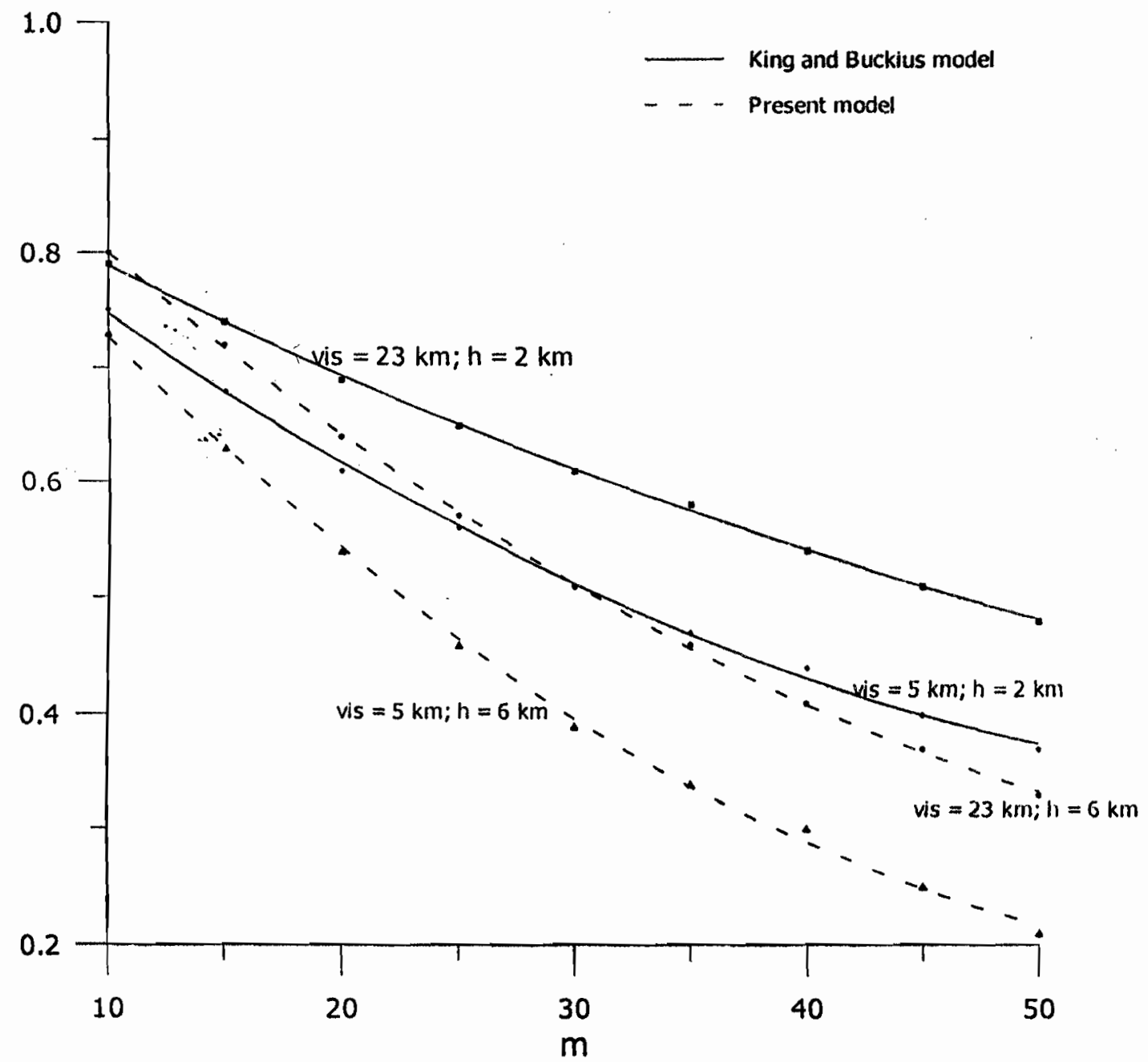

Figure 2: Variation of aerosol transmittance as a function of $m$ Note: Numerical estimates of $\tau$ for visibility (vis $=5 \mathrm{~km}, 23 \mathrm{~km}$ at the tropospheric height, $2 \mathrm{~km}$ ) were adapted from King and Buckuis (1979).

\section{Choice of values for the parameter ' $z$ '}

The attenuation of the solar beam as it traverses from the top of the atmosphere and arrives at the ground varies with the mass of the gases it encounters in its path. In the analysis that follows, altitudes between 100 and 600 $\mathrm{km}$ will represent the upper atmosphere while those below $100 \mathrm{~km}$ will be regarded as the lower atmosphere.

The principal layers in the upper atmosphere are produced by extreme ultraviolet and X-rays emitted from the sun as spectral lines and continuous radiation. In these regions, oxygen becomes dissociated into atoms by the action of solar uv radiation.

Each gas in the upper atmosphere, has its own scale height corresponding to its molar mass. The principles governing the dynamics of the upper atmosphere may be extended to the lower region where for instance ozone is formed through dissociating oxygen molecules. Various definitions are found in the literature for $=(e .9$. Rishbeth, 1988), but generally, $z$ is defined by equation (5).

McClatchey, et al. (1972) assembled data on the scattering and absorption coefficients as a funciion of altitude for the 1962 standard atmosphere and five other climate models (King and Buckius, 1979). Two types of the haze models have been employed in this work . vamely, the $23 \mathrm{~km}$ visual range (visibility) representing a $\mathrm{c}$ ? ar atmosphere and the $5 \mathrm{~km}$ visibility as a haze atmosphere. Visibility is often used to measure the level of aerosol density in the atmosphere. In fact, the transmittance due to aerosol scattering is a major factor in the assessment of turbidity levels at any location. The values of aerosol scaled height, $\mathrm{H}$ are evaluated from the data of McClatchey et al., as $H=1.58 \mathrm{~km}$ for visibility = $23 \mathrm{~km}$ and $H=1.73$ for visibility $=5 \mathrm{~km}$ for the purpose of analysis and comparison. The mid-altitude of the troposphere $(\sim 6 \mathrm{~km})$ has also been adopted for $h$ in equation (5). Consequently, $z=3.80$ for the clear atmosphere and $z=3.47$ for the haze atmosphere.

\section{RESULTS AND DISCUSSION}

Based on the analysis above, values of the integral transmittance for aerosol particles (atmospheric constituents, molecular fluctuations, maritime aerosol. waterfine droplets, dust and smoke, etc.) were obtained from equation (12) for various zenith angles but expressed in terms of the air mass, $m$ (See Table 1) where $m=\sec \chi(\chi=$ zenith angle of the sun). Necessary corrections of this relationship are significant at very large values of $\chi$ (Foitzik and Hinzpeter, 1958; Leckner, 1978). 


\section{Comparison with King and Bucklus Model}

The proposed expression (Equation 12) for the integral transmittance of atmospheric aerosols has been compared with a similar expression given by King and Buckius (1979). Some other expressions that could also have been used for the comparison were too complex and the parameters needed for computations are not easily available in the literature, or measured anywhere in Nigeria.

The results of the comparison are shown in Figure 2.

It is observed from the figure that the results of the two models are identical in trend but the magnitudes of the transmittances are not in exact agreement. The disparity in the magnitudes of the predicted transmittances of the two models appear to widen with increasing values of air mass, particularly for air mass $\geq 20$. This could be due to the differences in the tropospheric heights considered in the two models and the consideration of other parameters in the King and Buckius' expression which are not found in the new model. The simplicity of the proposed model is quite outstanding.

The results obtained using the scaled heights at $2 \mathrm{~km}$ altitude, gave values of reduced height not very convenient for the kind of trend expected from the study. For this reason, the mid-altitude height of the troposphere at approximately $6 \mathrm{~km}$, was adopted.

The proposed model may however find relevance in solar radiation modeling with respect to the evaluation of the transmittances of the various components of atmospheric gases including the broadband considerations of mixed gases, provided the reduced heights of the atmospheric 'constituents' are evaluated at tropospheric heights $\geq 6$ $\mathrm{km}$, probably up to an upper limit of $10 \mathrm{~km}$, with appropriate scaled heights of the atmospheric gas constituent.

\section{CONCLUSION}

A model for the direct transmittance of atmospheric aerosol has been developed. The proposed expression is derived along the lines used by Chapman (1931) for photoionization in the upper atmosphere.

The results of the proposed expression have been compared with those of a similar expression given by King and Buckius (1979). Plots of the two expressions indicate some differences in the magnitudes of the transmittance values, but the trends in their variations in general, are in good agreement

The proposed expression may be relevant for the prediction of the transmittances of other atmospheric gases at different strata of the atmosphere for solar radiation models, provided the scaled heights of the gases are evaluated at tropospheric heights probably in the limits $6 \mathrm{~km} \leq h \leq 10 \mathrm{~km}$.

\section{REFERENCES}

Bird, R. E. and Hulstrom, R. L., 1981. A simplified clear sky model for direct and diffuse isolation on horizontal surfaces: SERI TR-642-761. Golden, Colorado.

Bird, R. E. and Hulstrom R. L., 1982. Direct insolation models. Solar Energy Research Institute SERI TR-335-344, Golden, Colorado.
Chapman, S., 1931. The absorption and dissociative or ionizing effect of monochromatic radiation in an atmosphere on a rotating earth. Proc. Phys. Soc. 43: $26-45,484$.

Foitzik, L. and Hinzpeter, H., 1958. Sonnenstrahlung und Lufttrubung. Geest \& Portig K. -G., Leipzig.

Hoyt, D. V., 1978. A model for the calculation of solar global insolation. Solar Energy 21: $27-35$.

King, R. and Buckius, R. O., 1979. Direct solar transmittance for a clear sky. Solar Energy 22: $297-301$.

Leckner, B.: 1978. The spectral distribution of solar radiation at the earth's surface - Elements of a model. Solar Energy 20: 143 - 150.

Louche A., M. Maurel, G. Simonnot, G. Peri and M. Iqbal. 1987. Determination of Angstrom's turbidity coefficient from direct total solar irradiance measurements. Solar Energy 38(2): 89 - 96.

Maduekwe, A. A. L, and D. Oshodi-Glover. 1995. On the relationship between aerosol optical thirkness obtained from the meteorological range and monthly global horizontal radiation in Zaria. Nig. $\mathrm{j}$. Solar Energy 13: $7-15$

McClatchey, R. A., Fenn, R. W., Selby, J. E. A., Volz, F. E. and Garing, J. S., 1972. Optical properties of the Atmosphere. Air Force Cambridge Research Laboratories AFCRL-72-0497, Envir. Res. Paper No. 4.

Ohvril, H., Okulov, O., Teral H. and Teral, K., 1999. The atmospheric integral transparency coefficient and the Forbes Effect. Solar Energy 66(4): $305-317$.

Prasad, C. R., Inamdar A. K. and Venkatesh P., 1987. Computation of diffuse solar radiatión. Solar Energy $39(6)$ : $521-532$.

Psiloglou, B. E., Santamouris M. and Asimakopoulos

D.N., 1994. On the atmospheric water vapour transmission function for solar radiation models. Solar Energy 53: $445-453$.

Psiloglou, B. E., Santamouris M., and Asimakopoulos

D.N., 1995. Predicting the broadband transmittance of the uniformly mixed gases $\left(\mathrm{CO}_{2}, \mathrm{CO}, \mathrm{N}_{2} \mathrm{O}, \mathrm{CH}_{4}\right.$ and $\mathrm{O}_{2}$ ) in the atmosphere for solar radiation models. Renewable Energy 6: 63 - 70.

Rapti, A. S., 2000. Atmospheric transparency, atmospheric turbidity and climatic parameters. Solar Energy 69(2): 99 - 111.

Rishbeth, H., 1988. Basic Physics of the ionosphere: a tutorial review. J. Inst. Elect. Radio. Eng. 58(6): $\$ 207$ - \$223

Santamouris, M. J., R. Rigopoulos and Yianoulis P., 1985. $A$ note on an improved expression of the atmospheric $\mathrm{CO}_{2}, \mathrm{~N}_{2} \mathrm{O}, \mathrm{CH}_{4}$ and $\mathrm{O}_{3}$ integral transmission function. Atmos. Ocean 3: $313-316$ 